\title{
An Inexact Fuzzy Programming Approach for Power Coal Blending
}

\author{
W. Li ${ }^{*}$, G. H. Huang, C. Dong, and Y. Liu \\ MOE Key Laboratory of Regional Energy and Environmental Systems Optimization, Resources and Environmental Research Academy, North \\ China Electric Power University, Beijing 102206, China
}

Received 30 June 2011; revised 1 December 2012; accepted 28 January 2013; published online 27 June 2013

\begin{abstract}
In this paper, an inexact fuzzy coal blending model (IFCBM) was proposed for supporting the planning of coal blending process with the consideration of national standard for coals in burning boilers. This method integrated interval linear programming (ILP) and fuzzy linear programming (FLP) into a general framework, which could tackle the uncertainties expressed as interval numbers and fuzzy sets. Then the developed approach was applied to a case study of power coal blending management model, considering the environmental constraints for nitrogen oxide (NOx) emission and nitrogen oxide decomposition (De-NOx) process in power generation facilities. The generated decision alternatives could help decision makers identify the optimal power coal blending schemes under four pollutants removal policy scenarios, reflecting the tradeoffs between socio-economic and environmental benefits under desirable system reliability.
\end{abstract}

Keywords: power coal blending, air pollution emissions, interval fuzzy programming, scenario analysis, decision making, uncertainty

\section{Introduction}

Since the reform and opening-up, China's electricity consumption continues to grow rapidly correlating to the level economic development. In 2010, China's total power generation ranked first in the world and the power industry is a typical high energy consumption industry. Until renewable energy sources can reliably produce significant amounts of energy, the immediate energy demand is likely to be met by conventional fossil fuel combustion, such as coal. However, coal combustion produces a large amount of pollutant emissions, which are the chief contributors to global air pollution. Thus, blending coal technology is considered as a promising option to ensure the continued use of coal for electric power production. Also it is recommended as one of technologies which are technically attactive, economically viable, and environmentally conducive to meet the market and environmental requirements of coals (Guo et al., 2009; Huang et al., 2010; Yang et al., 2011a; Yang et al., 2011b; Lin et al., 2012; Riaza et al., 2012).

During the past decades, a number of systems analysis and optimization techniques were proposed to tackle the coal blending problems (Ruan et al., 2001; Xiao et al., 2002; Balat, 2007; Guo et al., 2009). For example, Ruan et al. (2001) developed an optimization expert system for coal blending based on the quantification nonlinear features of the relationship between blending and single coal characteristics. Xiao et al. (2002) pro-

${ }^{*}$ Corresponding author. Tel.: +86 10 61772976; fax: +86 1061772982.

E-mail address: weili1027@gmail.com (W. Li).

ISSN: 1726-2135 print/1684-8799 online

(C) 2013 ISEIS All rights reserved. doi:10.3808/jei.201300238 posed a diagnosis model to measure the coal ash slag-buildup characteristics by using an improved BP algorithm. Guo et al. (2009) conducted coal blending optimization of coal preparation production process based on adaptive simulated annealing genetic algorithm (ASAGA). However, in practice, coal properties vary from mine to mine and seam to seam. Parameters such as heating value, moisture, sulfur content, ash and its composition are in general in nature, inevitably generating multiple forms of uncertainty, especially for blending coal, which are important to keep the quality of coal in maintaining furnace rating and reliability (Chakraborty and Chandra, 2005). Besides, various parameters of system costs (i.e., coal resources exploration and utilization, as well as environmental treatment costs) usually vary with the changes of market and technologies improvement. Thus, the coal blending management models must effectively tackle the uncertainties associated to the model coefficients.

Previously, a large number of inexact programming methods have been developed to tackle the uncertainties and complexities in environment management systems. The most widely adopted technologies mainly include interval linear programming (ILP), stochastic linear programming (SLP), and fuzzy linear programming (FLP) (Tzeng et al., 1994; Huang et al., 1999; Huang, et al., 2001; Qin et al., 2006; Cai et al., 2007; Cai et al., 2009a-e; Li and Huang, 2008; Guo et al., 2008; Liu et al., 2009; Guo and Huang, 2009; Li et al., 2009; Huang and Cao, 2011; Fan and Huang, 2012). For instance, Lin and Huang (2008) proposed an interval-parameter energy systems model (IPEM) for effectively planning regional energy management systems under uncertainty. Liu et al. (2009) developed an inexact coupled coal and power management (ICCPM) model for supporting the coupled coal and power management sys- 
tems planning in north China. Cai et al. (2009c) established an interval-valued fuzzy robust programming (I-VFRP) model to determine desirable municipal solid-waste management schemes under uncertainty. Specifically, stochastic linear programming (SLP) could only tackle the uncertainty parameters with known probabilistic distributions which are hard to be get in reality. Comparatively, the interval linear programming (ILP) is an effective approach in dealing with parameters expressed as intervals with certain lower and upper bounds but difficult to solve other forms of uncertainties and needs to be combined with other methods. Furthermore, though the optimization technologies discussed above have been applied into many areas, they have rarely been introduced into coal blending management systems.

Therefore, in order to reflect the practical uncertainties existing in coal blending process, an inexact fuzzy coal blending model (IFCBM) will be proposed, which integrates inexact linear programming (ILP) and fuzzy linear programming (FLP) within a general optimization framework, tackling the uncertainties expressed as interval numbers and fuzzy sets. In this model, some parameters can be represented by interval numbers with known upper and lower bounds. Meanwhile, the flexibilities and fuzziness expressed as fuzzy sets and denoted as 'fuzzy constraints' and a 'fuzzy goal' are indicated by different membership grades corresponding to the degrees of satisfaction for the constraints and objective. Through considering the overall satisfaction, stable selections with the highest system satisfaction degrees under uncertainty will be generated (Huang et al., 2002; Gomez-Garcia et al., 2005; Skalska et al., 2010). Furthermore, environmental problems in the coal blending systems can be addressed in this model, such as the $\mathrm{NO}_{\mathrm{x}}$ and $\mathrm{SO}_{2}$ emitted from the process of coal combustion, and four scenarios will be established based on the combinations of desulphurization efficiencies and nitrogen oxide decomposition (De$\mathrm{NO}_{\mathrm{x}}$ ) process. Through computing the model, the generated solutions (such as the concrete coal blending patterns) could help decision makers identify desired coal blending management schemes under various social-economic and environmental conditions and balance the tradeoffs between system costs and reliability.

\section{Methodology}

An interval-parameter fuzzy linear programming (IFIP) problem can be formulated as follows (Huang et al., 1993; Li et al., 2007; Lin et al., 2008):

$\operatorname{Min} f^{ \pm} \cong C^{ \pm} X^{ \pm}$

Subject to:

$A^{ \pm} X^{ \pm} \leqq B^{ \pm}$

$X^{ \pm} \geq 0$

where $A^{ \pm} \in\left\{R^{ \pm}\right\}^{m \times n}, B^{ \pm} \in\left\{R^{ \pm}\right\}^{m \times l}, C^{ \pm} \in\left\{R^{ \pm}\right\}^{l \times n}, X^{ \pm} \in\left\{R^{ \pm}\right\}^{n \times l}$ and $\left\{R^{ \pm}\right\}$denotes a set of interval numbers; symbols “ $\cong$ ” and “” represent fuzzy equality and inequality (Cai et al., 2007). On the basis of the principle of fuzzy flexible programming, let $\lambda^{ \pm}$value correspond to the membership grade of satisfaction for a fuzzy decision. Specifically, the flexibility in the constraints and fuzziness in the system objective, which are represented by fuzzy sets and denoted as 'fuzzy constraints' and a 'fuzzy goal', respectively, are expressed as membership grades $\left[\lambda^{ \pm}\right]$ corresponding to the degrees of overall satisfaction for the constraints/objective. Thus, according to Huang et al. (1993) and Li et al. (2006), model (1) can be converted to:

$\operatorname{Max} \lambda^{ \pm}$

Subject to:

$$
\begin{aligned}
& C^{ \pm} X^{ \pm} \leq f^{+}-\left(1-\lambda^{ \pm}\right) \cdot\left(f^{+}-f^{-}\right) \\
& A^{ \pm} X^{ \pm} \leq b_{i}^{+}-\left(1-\lambda^{ \pm}\right) \cdot\left(b_{i}^{+}-b_{i}^{-}\right) \\
& X^{ \pm} \geq 0 \\
& 0 \leq \lambda^{ \pm} \leq 1
\end{aligned}
$$

where $f^{-}$and $f^{+}$are the lower and upper bounds of the objective's aspiration level, respectively; $\lambda^{ \pm}$is the control variable corresponding to the degree (membership grade) of satisfaction for the fuzzy decision. An interactive solution algorithm was developed to solve the above problem through analyzing the detailed interrelationships between the parameters and the variables and between the objective function and the constraints (Huang et al., 1995; Guo et al., 2008), through which model (2) can be divided into two deterministic sub-models, corresponding to the lower and upper bounds of the objective-function value (Huang et al., 1995). Then solutions are generated, representing the most optimistic and pessimistic solution sets. A sub-model corresponding to $\lambda^{+}$(when the objective function is to be maximized) is firstly formulated, and then the relevant sub-model corresponding to $\lambda^{-}$can be formulated based on the solution of the first sub-model. Thus the general solutions can be obtained as follows: $x_{\text {jopt }}^{ \pm}=\left[x_{\text {jopt }}^{-}, x_{\text {jopt }}^{+}\right], \lambda_{\text {opt }}^{ \pm}=\left[\lambda_{\text {opt }}^{-}, \lambda_{\text {opt }}^{+}\right]$ and $f_{\text {opt }}^{ \pm}=\left[f_{\text {opt }}^{-}, f_{\text {opt }}^{+}\right]$.

\section{Case Study}

In this case, four kinds of coals (A, B, C, and D) are provided to a $300 \mathrm{MW}$ thermal electric plant, which are all bituminous coals and their concrete characteristics are presented in Table 1. Furthermore, the air pollution control has been paid more attention in electric facilities in recent years. However, different power plants have different emission characteristics depending on the plant size, coal type, coal mineral matter content, combustion system, and boiler type, etc. Meanwhile, since $\mathrm{NO}_{\mathrm{x}}$ and $\mathrm{SO}_{2}$ emitted from the electric generating process are responsible for many environmental problems, $\mathrm{NO}_{\mathrm{x}}$ and $\mathrm{SO}_{2}$ 
Table 1. Properties Values of Blending Coals

\begin{tabular}{lllllllll}
\hline \multirow{2}{*}{ Coal } & \multicolumn{7}{c}{ Coal quality and index } \\
\cline { 2 - 8 } & $\mathrm{M}(\%)$ & $\mathrm{A}(\%)$ & $\mathrm{Q}(\mathrm{GJ} / \mathrm{t})$ & $\mathrm{V}(\%)$ & $\mathrm{S}(\%)$ & $\mathrm{C}(\mathrm{RMB})$ & $\mathrm{ST}$ & $\mathrm{HGI}\left({ }^{\circ} \mathrm{C}\right)$ \\
\hline A & {$[5.6,7.7]$} & {$[21.9,28.8]$} & {$[20.4,24.0]$} & {$[17.3,21.5]$} & {$[0.67,1.14]$} & {$[260,275]$} & {$[54.2,59.2]$} & {$[1239.2,1250.8]$} \\
B & {$[4.6,6.8]$} & {$[30.4,35.9]$} & {$[19.9,21.1]$} & {$[32.0,36.8]$} & {$[2.42,3.15]$} & {$[220,240]$} & {$[50.3,58.3]$} & {$[1198.3,1237.3]$} \\
C & {$[7.8,10.6]$} & {$[22.6,27.8]$} & {$[19.1,22.2]$} & {$[37.8,40.1]$} & {$[1.46,2.08]$} & {$[245,265]$} & {$[67.3,73.3]$} & {$[1352.4,1387.6]$} \\
D & {$[10.5,11.6]$} & {$[25.9,30.1]$} & {$[20.3,23.2]$} & {$[22.3,26.7]$} & {$[1.32,1.51]$} & {$[250,265]$} & {$[60.2,62.7]$} & {$[1375.7,1395.7]$} \\
\hline
\end{tabular}

constraints will be brought into models to make sure that results could satisfy both the latest national standards and profit demands of generation facilities (Shown as in Figure 1).

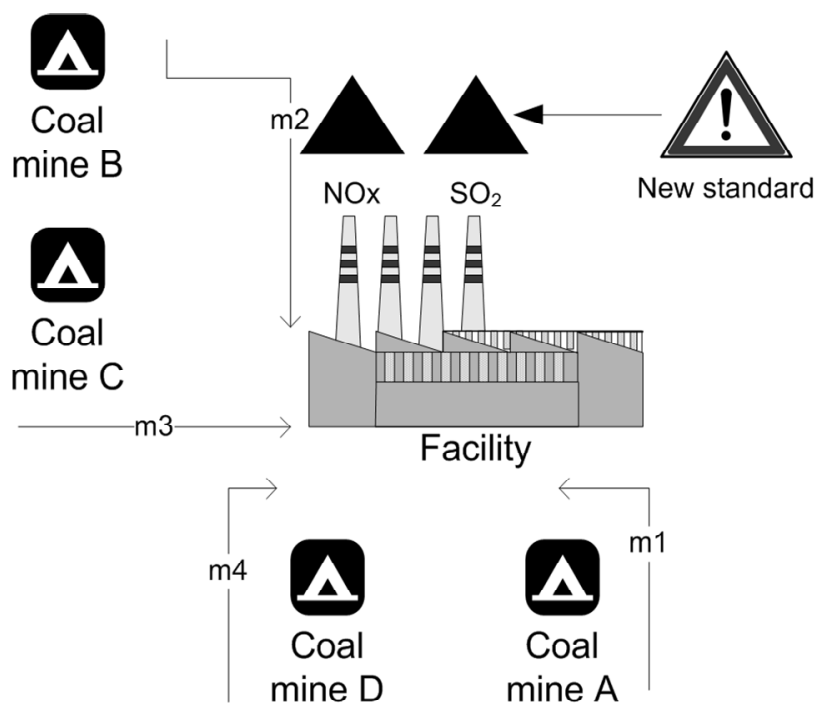

Figure 1. Structure of power coal blending system.

The target of coal blending is to search for a minimum economic and environmental cost, including purchasing cost for raw coal and treatment cost for sulfur and ash removal. And the constraints of coal blending mainly refer to the national standard restraints for different coal incinerators, such as heating value, moisture, sulfur content, ash content, volatile component, softening temperature of ash (ST), and hardgrove grindability index (HGI) of various kinds of coals, etc (Zhou et al., 2004). Then, an inexact fuzzy coal blending model (IFCBM) for coal blending under the consideration of environmental constraints for thionic and nitrogenous compound emissions is developed, and the specific formulations are presented as follows:

$$
M \text { in } f^{ \pm} \cong \sum_{i=1}^{I} C_{i}^{ \pm} m_{i}^{ \pm}+C A \cdot\left(\sum_{i=1}^{I} A_{i}^{ \pm} m_{i}^{ \pm}\right)+C S \cdot \eta \cdot\left(\sum_{i=1}^{I} S_{i}^{ \pm} m_{i}^{ \pm}\right)
$$

Subject to:

(a) Constraint for volatile component

$$
V_{\min }^{ \pm} \lesssim\left(\sum_{i=1}^{I} V_{i}^{ \pm} m_{i}^{ \pm}\right) / \sum_{i=1}^{I} m_{i}^{ \pm} \lesssim V_{\max }^{ \pm}
$$

(b) Constraint for heating value

$Q_{\min }^{ \pm} \lesssim\left(\sum_{i=1}^{I} Q_{i}^{ \pm} m_{i}^{ \pm}\right) / \sum_{i=1}^{n} m_{i}^{ \pm} \lesssim Q_{\max }^{ \pm}$

(c) Constraint for total heating value

$\sum_{i=1}^{I} Q_{i}^{ \pm} m_{i}^{ \pm} \cong \frac{E^{ \pm} \cdot H R^{ \pm}}{1000}$

(d) Constraint for moisture

$\left(\sum_{i=1}^{I} M_{i}^{ \pm} m_{i}^{ \pm}\right) / \sum_{i=1}^{I} m_{i}^{ \pm} \leqq M_{\max }^{ \pm}$

(e) Constraint for ash content

$\left(\sum_{i=1}^{I} A_{i}^{ \pm} m_{i}^{ \pm}\right) / \sum_{i=1}^{I} m_{i}^{ \pm} \leqq A_{\max }^{ \pm}$

(f) Constraint for sulfur content

$(1-\eta) \cdot\left(\sum_{i=1}^{I} S_{i}^{ \pm} m_{i}^{ \pm}\right) / \sum_{i=1}^{I} m_{i}^{ \pm} \lesssim S_{\max }^{ \pm}$

(g) Constraint for softening temperature of ash

$$
\left(\sum_{i=1}^{I} S T_{i}^{ \pm} m_{i}^{ \pm}\right) / \sum_{i=1}^{I} m_{i}^{ \pm} \leqq S T_{\max }^{ \pm}
$$

(h) Constraint for HGI

$$
\left(\sum_{i=1}^{I} H G I_{i}^{ \pm} m_{i}^{ \pm}\right) / \sum_{i=1}^{I} m_{i}^{ \pm} \lesssim H G I_{\text {max }}^{ \pm}
$$

(i) Constraint for nonnegative variables

$m_{i}^{ \pm} \geq 0, \forall i$

where $f=$ the total cost of coal blending system, $¥ / \mathrm{t}$; $i=$ differrent types of coals; $C_{i}=$ coal price per unit, $¥ / t$; $C A=$ treatment cost per unit of ash, ¥/t; $C S=$ desulphurization cost per unit, $¥ / \mathrm{t}$; $m_{i}=$ consumption of coal $i$ per year, t/year; $V_{i}=$ volatile 
Table 2. Allowable Property Values for De-NOx Constraints

\begin{tabular}{lllll}
\hline Property Parameter & $\mathrm{M}(\%)$ & $\mathrm{A}(\%)$ & $\mathrm{ST}$ & $\mathrm{S}(\%)$ \\
\hline Property Value & {$[9,11]$} & {$[30,32]$} & {$[60,64]$} & {$[0.51,1.00]$} \\
Property Parameter & $\mathrm{HGI}\left({ }^{\circ} \mathrm{C}\right)$ & $\mathrm{Q}(\%)$ & $\mathrm{V}(\%)$ & VN $(\%)$ \\
\hline Minimum Value & {$[1260,1280]$} & {$[18,21]$} & {$[15,16]$} & {$[25,27]$} \\
Maximum Value & {$[1330,1350]$} & {$[26,27]$} & {$[30,32]$} & {$[32,34]$} \\
\hline
\end{tabular}

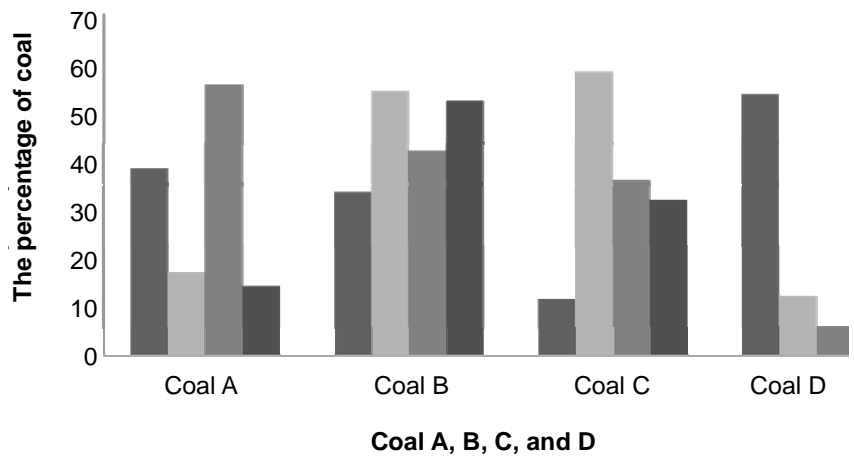

- Scenario a scenario b - Scenario c m Scenario d

Figure 2. The percentages of coals under different scenarios.

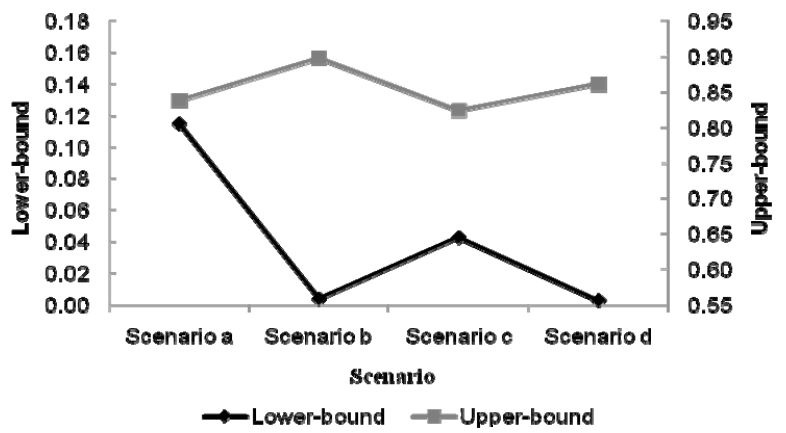

Figure 3. The system satisfication degrees under four scenarios.

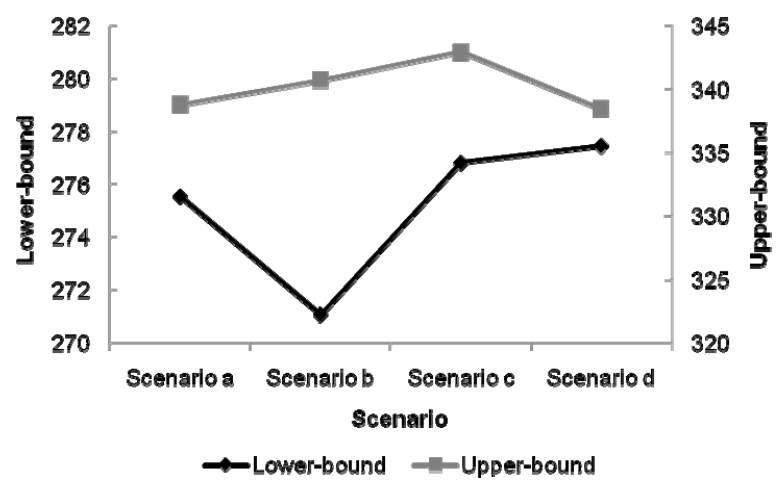

Figure 4. The system cost under foure scenarios $\left(10^{6} ¥ / a\right)$.

component value of coal $i$, \%; $Q_{i}=$ heating value of coal $i, \mathrm{GJ} / \mathrm{t}$; $M_{i}=$ moisture value of coal $i, \% ; A_{i}=$ ash content value of coal $i$, \%; $S_{i}=$ sulfur content value of coal $i$, \%; $S T_{i}=$ parameters of ST (softening temperature) of coal $i$; $H G I_{i}=$ parameters of HGI of coal $i$, ${ }^{\circ} \mathrm{C} ; V_{\max }, V_{\min }=$ the upper and lower limitation bound of volatile component; $Q_{\max }, Q_{\min }=$ the upper and lo- wer limitation bound of heating value; $M_{\max }=$ the upper limitation bound of moisture content; $A_{\max }=$ the upper limitation bound of ash content; $S_{\max }=$ the upper limitation bound of sulfur content; $S T_{\max }=$ the upper limitation bound of softening temperature of ash; $H G I_{\max }=$ the upper limitation bound of HGI; $S=$ total sulfur content limitation derived by conversion standard, \%; $E=$ annual power generation amount, $\mathrm{kWh}$; $H R=$ heat consumption for power generation per kWh of electricity, $\mathrm{MJ} / \mathrm{kWh} ; \eta=$ desulphurization efficiency.

In this model, according to the Development Research Center of the State Council (DRCNET), the new facilities which are approved for construction in the twelfth-five-year period could discharge $\mathrm{NO}_{\mathrm{x}}$ under $200 \mathrm{mg} / \mathrm{Nm}^{3}$ (dry basis), which requires burning coals consisting of more than $25 \%$ volatiles (daf). The cost for desulphurization and treatment cost for per unit of ash are chosen as [2.3, 4.0] and [7.8, 9.9] $¥ / t$, respectively. The consumption of heat value for per kWh of electricity is noted as [24.8, 27.9] MJ/kWh. By introducing GB/T 5795-1986 and National Emission Standards for Coal-fired Power Plants (NESCPP) into the constraints, two reduction targets are adopted: one is the coal property index under the present emission control (e.g. $\mathrm{SO}_{2}$ ) requirement; another is the stringent reducing objective of environment pollution in the future (e.g. De$\mathrm{NO}_{\mathrm{x}}$ ). And four scenarios are established according to the practical situations, including scenario a-Low desulphurization efficiency, b-High desulphurization efficiency, c-Low desulphurization efficiency with De- $\mathrm{NO}_{x}$, and d-High desulphurization efficiency with De- $\mathrm{NO}_{\mathrm{x}}$. Then, the inexact fuzzy programming approach is applied into this coal blending management system. According to the proposed method, the fuzzy sets will be introduced into the constraints for heating value, total heating value, moisture, ash content, sulfur content, softening temperature of ash, and HGI. Finally, the solutions (such as coal blending patterns) can be obtained under the preconditions of meeting the national standards requirements and minimizing the total cost of power generation.

\section{Results and Discussion}

Results under different scenarios (a to d) are shown in Table 3 and Figures 2 to 4 .

\subsection{Low Desulphurization Efficiency $(\boldsymbol{\eta}=0.5)$}

Limited by the low desulphurization efficiency, the amounts of coals A $\left(38.3 \times 10^{4} \mathrm{t} / \mathrm{a}\right)$ and $\mathrm{D}\left(53.5 \times 10^{4} \mathrm{t} / \mathrm{a}\right)$ would be several times larger than those of coals $B\left([5.4,33.5] \times 10^{4} \mathrm{t} / \mathrm{a}\right)$ and $C\left(11.5 \times 10^{4}\right.$ t/a). Shown as Table 1 and Figures 3 and 4, the total sulfur contents in coals $\mathrm{B}$ and $\mathrm{C}$ would be at high levels, thus the amounts of coals $B$ and $C$ (considered as midhigh-sulfur coal) blended in must be cut to low level to fulfill the requirement of the environmental standards. Since the satisfaction degrees $\lambda^{ \pm}$represent the probability of satisfying the objective function and constraints, the upper bound of variable is corresponding to the lower bound of $\lambda^{ \pm}$, while the lower bound is corresponding to the upper bound of $\lambda^{ \pm}$, which would all decrease with increase of satisfaction degree. Specifically, the 
Table 3. Results of IFCBM

\begin{tabular}{lllllll}
\hline $\begin{array}{l}\text { Whether or not } \\
\text { consider De-NOx }\end{array}$ & Desulphurization efficiency & Scenario & $\begin{array}{l}\text { Coal A } \\
\left(\times 10^{4} \mathrm{t} / \mathrm{a}\right)\end{array}$ & $\begin{array}{l}\text { Coal B } \\
\left(\times 10^{4} \mathrm{t} / \mathrm{a}\right)\end{array}$ & $\begin{array}{l}\text { Coal C } \\
\left(\times 10^{4} \mathrm{t} / \mathrm{a}\right)\end{array}$ & $\begin{array}{l}\text { Coal D } \\
\left(\times 10^{4} \mathrm{t} / \mathrm{a}\right)\end{array}$ \\
\hline No & $\eta=0.5$ & $\mathrm{a}$ & {$[38.3,38.3]$} & {$[5.4,33.5]$} & {$[11.5,11.5]$} & {$[53.5,53.5]$} \\
& $\eta=0.9$ & $\mathrm{~b}$ & {$[17.1,17.1]$} & {$[54.3,54.3]$} & {$[30.4,58.3]$} & {$[12.1,12.1]$} \\
Yes & $\eta=0.5$ & $\mathrm{c}$ & {$[55.7,55.7]$} & {$[12.4,41.8]$} & {$[35.9,35.9]$} & {$[5.9,5.9]$} \\
& $\eta=0.9$ & $\mathrm{~d}$ & {$[0,14.1]$} & {$[52.3,52.3]$} & {$[31.9,31.9]$} & {$[30.7,41.9]$} \\
\hline
\end{tabular}
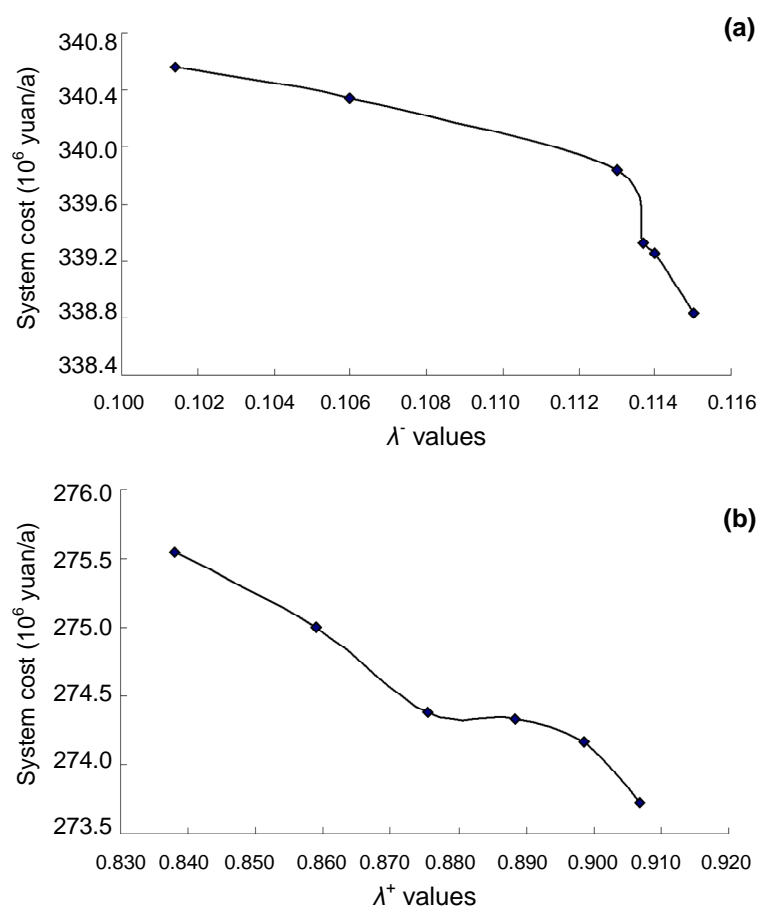

Figure 5. System costs under $\lambda^{-}$and $\lambda^{+}$values.

blending amount of coal B would decrease when the degree of satisfaction $\left(\lambda^{ \pm}\right)$increases, for instance, which means that it would undertake a larger system risk when blending more coal B, though the price of coal B is very low.

\subsection{High Desulphurization Efficiency $(\boldsymbol{\eta}=0.9)$}

In this situation, thorough-going changes would be generated in the blending amounts of coals A, B, C and D. Since more funds and techniques are employed for desulphurization, mid-high-sulfur coal could be fully used and much more of them could be blended with the low-sulfur coal. Then, coals B and $\mathrm{C}$ would be blended more than $\mathrm{A}$ and $\mathrm{C}$ due to their price advantage. Compared to scenario a, the blending amounts of coals B and C would be 54.3 and $[30.4,58.3] \times 10^{4} \mathrm{t} / \mathrm{a}$, while coals A and D would be 17.1 and $12.1 \times 10^{4}$ t/a. Similarly as scenario a, the increased amount of coal $C$ would decrease with increase of the system satisfaction degree. Moreover, coal C would be the best choice when the blending amount increases, which may be influenced by the higher limitation of desulphurization efficiency and the lowest cost per heating value.
4.3. Low Desulphurization Efficiency ( $\boldsymbol{\eta}=0.5$ ) with De-NO

Low $\mathrm{NO}_{\mathrm{x}}$ combustion technology is now wildly adopted in power generation facilities in China, but it is far than enough to fulfill the $\mathrm{NO}_{\mathrm{x}}$ emission standard established in the near future $\left(200 \mathrm{mg} / \mathrm{m}^{3}\right.$ in the draft of NESCPP). According to the Coal and $\mathrm{NO}_{\mathrm{x}}$ Conversion Rate (CNCR) in the Handbook of discharge coefficients for industrial pollutions in first national survey of pollution sources (Volume X), only when the lower limitation bound of volatile component is raised to [25, 27] \% and De- $\mathrm{NO}_{\mathrm{x}}$ technology (e.g. selective catalytic reduction) is adopted, NOx emissions could be cut into a normal level limited by the new standard. As a result, the quantities of four kinds of coals pouring into the boiler would change with their respective properties. Owing to the stricter constraints for volatile, high volatile bituminous coals $\mathrm{A}$ and $\mathrm{C}$ would be used in large amounts. Specifically, quantities of coals A, B, C and D would be [55.7, 55.7], [12.4, 41.8], [35.9, 35.9] and [5.9, 5.9] $\times 10^{4} \mathrm{t} / \mathrm{a}$ in this state. The amount of coal $\mathrm{C}$ would be more than that in scenario a for its high volatile, in spite of its higher price and higher sulfur content when the De- $\mathrm{NO}_{\mathrm{x}}$ is considered. And the degrees of satisfaction would decline to [0.043, 0.824] compared to $[0.115,0.838]$ in scenario a.

\subsection{High Desulphurization Efficiency $(\eta=0.9)$ with De- $\mathrm{NO}_{\mathrm{x}}$}

In this scenario, [0, 14.1], 52.3, 31.9 and [30.7, 41.9] $\times 10^{4}$ $\mathrm{t} / \mathrm{a}$ would be the suggested blending amount of coal A, B, C and $\mathrm{D}$. Due to the higher desulphurization efficiency than scenario c, coals B, C and D would be blended more than A for their higher quantities of volatile component in spite of their higher quantities of sulfur content. The blending amounts of $\mathrm{A}$ and D would increase with the decrease of satisfaction degrees of this system. Surely, total cost of this strictest scenario would be the highest. Compared to scenario b, blending amount of coal D would make a sharp growth, for coal D is believed to have a higher performance price ratio than that in scenario b. Since the quantity of volatile component in coal D is higher than that in coal A, and the high desulphurization efficiency make us neglect its high sulfur content.

As shown in Table 3, the total system costs would vary according to the different environmental requirements under various degrees of satisfaction ( $\lambda^{ \pm}$values). Specifically, the system cost would be [275.552, 338.830] $\times 10^{6} ¥ / a$ under scenario a, [271.065, 340.734] $\times 10^{6} ¥ / a$ under scenario b, [276.826, 3 42.956] $\times 10^{6} ¥ / \mathrm{a}$ under scenario c, and [272.471, 338.452] $\times$ $10^{6} ¥ / a$ under scenario d, with their degrees of satisfaction $\left(\lambda^{ \pm}\right.$ 
values) being [0.115, 0.838], [0.004, 0.898], [0.043, 0.824], and $[0.003,0.861]$, respectively. Decision alternatives can be acquired by adjusting the decision variable values within their solutions intervals which are flexible in reflecting the variations of system conditions introduced by uncertainties, while the deterministic solutions are not affected by uncertainties. Therefore, the two decision projects corresponding to the upper and the lower bounds of $f^{ \pm}$represent two extreme decisions concerning the trade-off of environmental and economic. In other words, the results indicate that planning the energy system without treatment of nitrogen oxides would lead to a lower system cost; in comparison, planning with a high system cost would lead to lower emissions. Thus, the trade-off between economic development and environmental risks can be reflected by the interval solutions.

The $\lambda^{ \pm}$value represents the probability of satisfying the objective function and constraints under the given system conditions in accordance with the decision makers' preference regarding environmental and economic tradeoffs. In detail, $\lambda^{-}$corresponds to a high system cost and high decision variable values, while $\lambda^{+}$corresponds to low system cost and low decision variable values. Generally, the expected system cost would decrease and the satisfaction degree would increase as the $\lambda^{ \pm}$level is raised; in comparison, the system cost would increase and the satisfaction degree would decrease as the $\lambda^{ \pm}$level is reduced (Li and Huang, 2008). The relationship between lowerbound system costs and $\lambda^{+}$values would adhere to the same change regularity (shown in Figure 5). For instance, the system cost would reach to $¥ 340.56$ million with the satisfaction degree being 0.838 (the minimum $\lambda^{+}$value); in contrast, the system cost would decrease to $¥ 273.72$ million with the satisfaction degree being 0.907 (the maximum $\lambda^{+}$value).

\section{Conclusions}

With the continuous improvement of the operating system and technology for thermal power generation units, the technical requirements and environmental standards for thermal reactors have become much stricter. And besides, mid-high-sulfur coals consist more than $20 \%$ of the coal mining resources in China. Thus, in order to effectively utilize various kinds of coals and protect the environment, it is significantly important to blend mid-high-sulfur coals into the coals in high grade, which can also bring total cost cut. Therefore, in this study, an inexact fuzzy coal blending model (IFCBM) was developed for the planning of power coal blending management systems, which was an integration of interval linear programming and fuzzy linear programming. Specifically, this study could: (1) tackle the uncertainties expressed as both interval numbers and fuzzy sets; (2) provide optimal solutions for decision makers under their desirable system satisfaction degrees; (3) generate effective coal blending schemes under four pollutants removal policy scenarios, helping balance the tradeoffs between environmental requirements and system costs; (d) conclude that if mid-high-sulfur coal is burned in the coal power plant with higher desulphurization ratio, system cost and the total pollutant amount will both decrease.
Acknowledgments. This research was supported by the Ministry of Education of the P.R.C.(No.708017) and "the Fundamental Research Funds for the Central Universities".

\section{References}

Balat, M. (2007). Influence of coal as an energy source on environmental pollution. Energy Sources Part A Recovery, Utilization, Environ. Effects, 29(7), 581-589. http://dx.doi.org/10.1080/155670 30701225260

Cai, Y.P., Huang, G.H., Nie, X.H., Li, Y.P., and Tan, Q. (2007). Municipal solid waste management under uncertainty: a mixed interval parameter fuzzy-stochastic robust programming approach, Environ. Eng. Sci., 24(3), 338-352. http://dx.doi.org/10.1089/ees. 2005.0140

Cai, Y.P., Huang, G.H., Yang, Z.F., Lin, Q.G., and Tan, Q. (2009a). Community-scale energy systems planning under uncertainty - An interval chance-constrained programming approach, Renew. Sust. Energ. Rev., 13(4), 721-735. http://dx.doi.org/10.1016/j.rser. 2008. 01.008

Cai, Y.P., Huang, G.H., Bass, B., Nie, X.H., and Tan, Q. (2009b). An optimization-model-based interactive decision support system for regional environmental and energy management systems planning under uncertainty, Expert Syst. Appl., 36(2), 3470-3482. http://dx. doi.org/10.1016/j.eswa.2008.02.036

Cai, Y.P., Huang, G.H., Lu, H.W., and Yang, Z.F. (2009c). I-VFRP: An interval-valued fuzzy robust programming approach for environmental management planning under uncertainty, Eng. Optimiz., 41(5), 399-418. http://dx.doi.org/10.1080/03052150802488381

Cai, Y.P., Huang, G.H., and Tan, Q. (2009d). An inexact optimization model for regional energy systems planning in the mixed stochastic and fuzzy environment, Int. J. Energy Res., 33(5), 443-468. http://dx.doi.org/10.1002/er.1483

Cai, Y.P., Huang, G.H., Yang, Z.F., and Tan, Q. (2009e). Planning of community-scale energy management systems in mixed stochastic and fuzzy environment, Renewable Energy, 34(7), 1833-1847. http://dx.doi.org/10.1016/j.renene.2008.11.024

Chakraborty, M., and Chandra, M.K. (2005). Multicriteria decision making for optimal blending for beneficiation of coal: a fuzzy programming approach, Omega, 33, 413-418. http://dx.doi.org/10.101 6/j.omega.2004.07.005

Fan, Y.R, and Huang, G.H. (2012). A robust two-step method for solving interval linear programming problems within an environmental management context, J. Environ. Inf., 19(1), 1-12. http://dx. doi.org/10.3808/jei.201200203

Gomez-Garcia, M.A., Pitchon, V., and Kiennemann, A. (2005). Pollution by nitrogen oxides: an approach to NOx abatement by using sorbing catalytic materials, Environ. Interact, 31, 445-467. http:// dx.doi.org/10.1016/j.envint.2004.09.006

Guo, P., Huang, G.H., He, L., and Cai, Y.P. (2008). ICCSIP: an inexact chance-constrained semi-infinite programming approach for energy systems planning under uncertainty, Energy Sources Part A Recovery Util. Environ. Effects, 30(14/15), 1345-1366. http://dx.doi.org/10.1080/15567030801928961

Guo, P., and Huang, G.H. (2009). Inexact fuzzy-stochastic mixed integer programming approach for long-term planning of waste management - part B: case study, J. Environ. Manage., 91, 441460. http://dx.doi.org/10.1016/j.jenvman.2009.09.015

Guo, X.J., Chen, M., and Wu, J.W. (2009). Coal blending optimization of coal preparation production process, Procedia Earth Planet. Sci., 1, 654-660. http://dx.doi.org/10.1016/j.proeps.2009.09.103

Huang, G.H., Baetz, B., and Patry, G. (1992). An interval linear programming approach for municipal solid waste management planning under uncertainty, Civ. Eng. Syst., 9(3), 319-335. http://dx. doi.org/10.1080/02630259208970657 
Huang, G.H., Baetz, B., and Patry, G. (1993). A grey fuzzy linear programming approach for municipal solid waste management planning under uncertainty, Civ. Eng. Syst., 10(1), 123-146. http:// dx.doi.org/10.1080/02630259308970119

Huang, G.H., Baetz, B., and Patry, G. (1995). Grey integer programming: an application to waste management planning under uncertainty, Eur. J. Oper. Res., 83(3), 594-620. http://dx.doi.org/10.10 16/0377-2217(94)00093-R

Huang, G.H., Chen, Z., Tontiwachwuthikul, P., and Chakma, A. (1999). Environmental risk assessment for underground storage tanks through an interval parameter fuzzy relation analysis approach, Energ. Sources Part A, 21(1/2), 75-96. http://dx.doi.org/10. 1080/00908319950014975

Huang, G.H., Sae-Lim, N., Liu, L., and Chen, Z. (2001). An intervalparameter fuzzy-stochastic programming approach for municipal solidwaste management and planning, Environ. Model. Assess., 6(2), 271-283. http://dx.doi.org/10.1023/A:1013394118863

Huang, G.H., and Cao, M.F. (2011). Analysis of Solution Methods for Interval Linear Programming, J. Environ. Inf., 17(2), 54-64. http://dx.doi.org/10.3808/jei.201100187

Huang, Q., Cheng, S.Y., Li, Y.P., Li, J.B., Chen, D.S., and Wang, H.Y. (2010). An Integrated MM5-CAMx Modeling Approach for Assessing PM10 Contribution from Different Sources in Beijing, China, J. Environ. Inf., 15(2), 47-61. http://dx.doi.org/10.3808/jei.201000 166

Huang, Y.F., Baetz, B.W., Huang, G.H., and Liu, L. (2002). Violation analysis for solid waste management systems: an interval fuzzy programming approach, J Environ. Manage., 65, 431-446. http:// dx.doi.org/10.1006/jema.2002.0566

Li, Y.P., Huang, G.H., and Nie, S.L. (2007). Mixed interval-fuzzy two-stage integer programming and its application to flood- diversion planning, Eng. Optimiz., 39(2), 163-183. http://dx.doi.org/10. 1080/03052150601044831

Li, Y.P., and Huang, G.H. (2008). IFMP: Interval-fuzzy multistage programming for water resources management under uncertainty, Resour. Conserv. Recycling, 52(5), 800-812. http://dx.doi.org/10. 1016/j.resconrec.2007.11.007

Li, Y.P., Huang, G.H., Huang, Y.F., and Zhou, H.D. (2009). A multistage fuzzy-stochastic programming model for supporting sustainable water-resources allocation and management, Environ. Model. Software, 24 (6), 786-797. http://dx.doi.org/10.1016/j.envsoft. 2008.11.008

Lin, B.Q., Wu, Y., Zhang, L. (2012). Electricity saving potential of the power generation industry in China, Energy, 40, 307-316. http: //dx.doi.org/10.1016/j.energy.2012.01.069

Lin, Q.G., and Huang, G.H. (2008). IPEM: An interval-parameter energy systems planning model, Energ. Sources Part A, 30, 13821399. http://dx.doi.org/10.1080/15567030801929043

Liu, Y., Huang, G.H., Cai, Y.P., Cheng, G.H., Niu, Y.T., and An, K. (2009). Development of an inexact optimization model for coupled coal and power management in North China, Energy Policy, 37(12), 4345-4363. http://dx.doi.org/10.1016/j.enpol.2009.05.050

National Quality and Technical Supervision Agency. GB/T 57951986. (1986). Standard Book of China, Beijing, Standards Press of China.

Qin, X.S., Huang, G.H., Huang, Y.F., Zeng, G.M., Chakma, A., and Li, J.B. (2006). NRSRM: a decision support system and visualization software for the management of petroleum-contaminated sites, Energ. Sources Part A, 28(3), 199-220. http://dx.doi.org/10.1080/ 009083190889951

Riaza, J., Gil, M.V., Álvarez, L., Pevida, C., Pis, J.J., and Rubiera, F. (2012). Oxy-fuel combustion of coal and biomass blends, Energy, 41, 429-435. http://dx.doi.org/10.1016/j.energy.2012.02.057

Ruan, W., Zhou, J. H., Cao, X. Y., and Cen, K. F. (2001). Study and application of the expert system for coal blend, Power Eng., 21(6), 1572-1575. In Chinese

Skalska, K., Miller, J., and Ledakowicz, S. (2010). Trends in NOx abatement: a review, Sci. Total Environ., 408, 3976-3989. http://dx. doi.org/10.1016/j.scitotenv.2010.06.001

The handbook of discharge coefficients for industrial pollutions in first national survey of pollution sources

Tzeng, G.H., Shiau, T.A., and Teng, J.Y. (1994). Multiobjective decision-making approach to energy supply mix decisions in Taiwan, Energ. Sources Part A, 16(3), 301-316. http://dx.doi.org/10.1080/ 00908319408909080

Xiao, J., Lv, Z.Z., and Wang, J. (2002). A Model for the Diagnosis of Coal Ash Slag-buildup Characteristics by Using an Improved BP Algorithm, Heat Energ. Power Eng., 17(99), 271-275.

Yang, Z.F., Li, S.S., Zhang, Y., and Huang, G.H. (2011a). Energy Synthesis for Three Main Industries in Wuyishan City, China, $J$. Environ. Inf., 17(1), 25-35. http://dx.doi.org/10.3808/jei.2011001 84

Zhou, Q., Huang, G.H., and Chan, C.W. (2004). Development of an intelligent decision support system for air pollution control at coalfired power plants, Expert Syst. Appl., 26, 335-356. http://dx.doi. org/10.1016/j.eswa.2003.09.005 